\title{
Assessment of Risk Factors for Iron Deficiency Anemia in Infants and Young Children: A Case-Control Study
}

\author{
Audrone Muleviciene, ${ }^{1}$ Natalija Sestel, ${ }^{2}$ Sigita Stankeviciene, Daiva Sniukaite-Adner, ${ }^{3}$ \\ Roma Bartkeviciute, Jelena Rascon, and Augustina Jankauskiene ${ }^{1}$
}

\begin{abstract}
Introduction: Iron deficiency anemia (IDA) is common in children aged 0-35 months in Lithuania. Nevertheless, there are no studies investigating IDA in this age group. We aimed to identify the major risk factors for disease development focusing on medical history and dietary habits.

Methods: A prospective case-control study was conducted in a university hospital. The enrolled cohort was divided into three groups: IDA infants (IDA-In; $n=36$, aged 3-11 months), IDA children (IDA-Ch; $n=23$, aged 12-32 months), and healthy controls (HCs; $n=32$, aged 6-34 months).

Results: There was a higher number of premature, low birth weight (LBW), and faster gaining weight infants in the IDA-In group. Their diet diversity was lower than IDA-Ch and HC. In contrast, the IDA-Ch group had no signs of impaired iron stores at birth or higher iron need for fast growth; their diet diversity was similar to that of HC, but meat was introduced later as compared with those in the IDA-In and HC groups. Consumption of cow's milk was rather low among all study participants, but consumption of sugar-added products was found to be a new emerging problem. Exclusive breastfeeding did not differ in duration and prevalence; the age for introduction of complementary foods was similar in all groups.

Conclusions: Low compliance with World Health Organization (WHO) recommendations on breastfeeding and complementary feeding suggests an urgent need for nutritional counseling in early childhood, especially in premature, LBW, and fast gaining weight infants.
\end{abstract}

Keywords: iron deficiency, nutritional anemia, exclusive breastfeeding, complementary feeding

\section{Introduction}

A NEMIA IS A MAJOR public health issue affecting about 2.5 billion people worldwide. Preschool children are the only age group with an increasing prevalence of anemia globally. ${ }^{1}$ Iron deficiency (ID) is responsible for development of anemia in $50 \%$ of cases. ${ }^{1}$ Infants and young children are the most vulnerable because of low body iron stores and poor nutritional intake. ${ }^{2}$ ID anemia (IDA) in infancy and early childhood results in long-term health consequences: impaired psychomotor development, lower educational achievement, and lower socioeconomic status. ${ }^{2}$ Thus, ID and IDA prevention should be given a high priority. ${ }^{2}$
According to World Health Organization (WHO) guidelines, appropriate nutrition and micronutrient supplementation for infants and young children should be given the greatest attention. ${ }^{2}$ Breast milk (BM) provides high-bioavailable iron, thus exclusive breastfeeding is considered as an ID preventive measure and recommended for all infants in their first 6 months of life. ${ }^{2}$ At the age of 6 months, complementary food rich in energy, macronutrients, and micronutrients, especially iron, should be introduced. ${ }^{2,3}$ Diet diversity is crucial for meeting nutritional requirements. ${ }^{2}$ Continued breastfeeding for the first 2 years of age and beyond is recommended, as BM provides $\sim 40 \%$ of total energy needs and is a source of essential fatty acids, high bioavailable

\footnotetext{
${ }^{1}$ Clinic of Children's Diseases, Institute of Clinical Medicine, Faculty of Medicine, Vilnius University, Vilnius, Lithuania.

${ }^{2}$ Centre for Pediatric Oncology and Hematology, Children's Hospital, Affiliate of Vilnius University Hospital Santaros Klinikos, Vilnius, Lithuania.

${ }^{3}$ Lithuanian Lactation and Breastfeeding Consultants Association, Vilnius, Lithuania.

${ }^{4}$ Department of Public Health, Institute of Health Sciences, Faculty of Medicine, Vilnius University, Vilnius, Lithuania.
} 
vitamins and minerals, and promotes healthy growth and development of the child. ${ }^{2-4}$

Low birth weight (LBW) infants (premature and LBW for gestational age) have lower body iron stores, experience greater blood loss (because of more frequent need for intensive care and phlebotomies), and have higher nutritional iron needs for catch-up growth. ${ }^{5}$ Although the WHO recommends enteral iron supplementation only for very LBW newborns, ${ }^{6}$ there is certain evidence that LBW infants would also benefit from iron supplementation. ${ }^{7,8}$

Lithuania, a country in North Eastern Europe, is a member of WHO and has adopted these recommendations in its national law and prepared methodological materials for its healthcare providers. Even so, significant gaps are observed in national breastfeeding policy and practice, ${ }^{9}$ the primary prophylaxis of nutritional anemia.

Alarmingly, an increasing prevalence of anemia in infants and young children ( $0-35$ months of age) was observed in the past decade. According to the data on health statistics, ${ }^{10}$ the prevalence of anemia has more than doubled in this group in the 5-year period from 2010 to 2014: from 16.6 to 35.8 cases per 1,000 children. ID was the most common etiology of anemia. Moreover, it is estimated that every second Lithuanian child experiences ID in the first 2 years of life. ${ }^{11}$ Despite this frequency, no recent studies have investigated the factors contributing to this increase or documenting adherence in $\mathrm{Li}$ thuania to WHO breastfeeding and complementary feeding recommendations for infants and young children. Indeed, increasing prevalence of breastfeeding is argued to be negatively associated with IDA and recommendations to start complementary feeding as early as 4 months of age (according to the European Society for Pediatric Gastroenterology, Hepatology and Nutrition) are promoted by healthcare specialists.

Therefore, we carried out a case-control study in Vilnius region focusing on nutritional IDA in the first 3 years of life, pursuing the aim to compare breastfeeding practices and dietary habits of anemic infants and children up to 36 months of age with those of the healthy controls.

\section{Materials and Methods}

A prospective case-control study was conducted in a university hospital. The study was approved by the Vilnius Regional Bioethical Committee.

Based on the WHO criteria, nutritional IDA was defined as follows: (1) serum hemoglobin $<110 \mathrm{~g} / \mathrm{L}$, (2) ferritin level $<12 \mu \mathrm{g} / \mathrm{L}$ and/or reticulocyte-hemoglobin equivalent $<28 \mathrm{pg}$, and (3) after other etiological factors of ID excluded. ${ }^{12,13}$ Mild, moderate, and severe IDA was defined as hemoglobin concentration 109-100, 99-70, and <70 g/L, respectively. ${ }^{12}$

Infants and young children diagnosed with nutritional IDA in the first 3 years of life were enrolled in the study if they met the inclusion criteria: (1) an otherwise healthy child and not having taken any medication for at least 4 weeks before the enrollment, (2) singleton pregnancy, and (3) living in Vilnius. The patients were divided into two groups according to age: $<12$ months (further-IDA infants) and 12-36 months (furtherIDA children). Healthy children aged 6-35 months (meeting the inclusion criteria already described but without IDA) were recruited as a control group.

Detailed medical data were collected by using a standard validated questionnaire. Mothers reported their breastfeeding practices, timing of introduction of complementary food, and socioeconomic status. For data analysis, we used WHO terms and definitions ${ }^{14}$ :

- exclusive breastfeeding-infants received only BM (directly from the breast or an expressed BM) without any food or drink, not even water, except for oral rehydration solutions, medicines, and vitamins under medical indications;

- complementary feeding-infants received solid, semisolid, or soft foods and any liquids along with BM;

- continued breastfeeding-infants or children were breastfed along with foods appropriate for their age.

Diet diversity was adopted from WHO guidelines ${ }^{14}$ and defined as consumption of four or more food groups except for BM or infant formula: vegetables and fruits, cereals (including whole grain bread), meat, fish, eggs, and dairy products (including only unsweetened products of sour milk and cottage cheese). To assess consumption of sugar-added products, parents reported the consumption of sweetened dairy products, canned juice, cookies, sweets, and chocolates.

Statistical analysis was performed with $\mathrm{R}$ software package (version 3.3.2). As continuous variables were non-normally distributed, they are provided as median and interquartile range. They were compared using the Kruskal-Wallis rank sum test. Categorical variables are provided in absolute numbers and percentages and were compared using Pearson's chi-squared test. When number of observations were $<5$, Fisher's exact test was applied. A $p$-value $<0.05$ was considered as statistically significant.

\section{Results}

During the period 2016-2018, totally 197 children (82 [42\%] girls and 115 [58\%] boys) $<3$ years of age were examined by pediatric hematologist due to suspicion of nutritional IDA. Only 66 IDA infants and children were eligible for the study. Parents of seven patients refused to participate in the study or did not return the questionnaire. Finally, the study included 36 IDA infants (IDA-In), 23 IDA children (IDA-Ch), and 32 healthy controls (HCs) (Table 1). Nutritional IDA was diagnosed at the median age of 8.5 (3) months in the first group and 15 (6.5) months in the second group. However, there were 4 (11\%) infants diagnosed as early as 3-5 months. Mild anemia was diagnosed in about $50-60 \%$ of IDA cases in both groups. Two infants and one child were diagnosed with severe IDA.

The majority of study participants in all groups were mature and vaginally delivered. Parental age, education level, and prevalence of anemia in pregnancy also did not differ.

There were more boys, premature, and LBW patients in the IDA infants group than in the remaining groups $(p<0.05)$. IDA infants doubled their birth weight earlier than IDA children and healthy controls $(p<0.05)$. Despite this, prophylactic iron supplementation did not differ significantly between groups.

All children initiated breastfeeding soon after birth. Nevertheless, the prevalence of exclusive breastfeeding was rather low and did not differ significantly between groups in the first month of life (Fig. 1), as supplementation with waterbased liquids or formula was common in postnatal wards (Fig. 2). Later, more study participants were exclusively 
Table 1. Basic Characteristics of the Study Participants

\begin{tabular}{|c|c|c|c|}
\hline & $\begin{array}{l}\text { IDA infants } \\
\quad(\mathrm{n}=36)\end{array}$ & $\begin{array}{l}\text { IDA children } \\
\quad(\mathrm{n}=23)\end{array}$ & $\begin{array}{l}\text { Healthy controls } \\
\quad(\mathrm{n}=32)\end{array}$ \\
\hline $\begin{array}{l}\text { Hemoglobin, g/L, median }(\mathrm{IQR})^{\mathrm{a}, \mathrm{b}} \\
\text { Mild anemia, } n(\%)^{\mathrm{c}} \\
{\text { Moderate anemia, } n(\%)^{\mathrm{c}}}^{\text {Severe anemia, } n(\%)^{\mathrm{c}}}\end{array}$ & $\begin{array}{r}100(13) \\
19(52) \\
15(42) \\
2(6)\end{array}$ & $\begin{array}{r}101(12) \\
14(61) \\
8(35) \\
1(4)\end{array}$ & 118 (12) \\
\hline $\begin{array}{l}\text { Natural delivery, } n(\%)^{\mathrm{c}} \\
\text { Male gender, } n(\%)^{\mathrm{b}, \mathrm{c}}\end{array}$ & $\begin{array}{l}28(78) \\
25(70)\end{array}$ & $\begin{array}{l}16(70) \\
12(52)\end{array}$ & $\begin{array}{l}24(75) \\
11(34)\end{array}$ \\
\hline $\begin{array}{l}\text { Gestational age, weeks, median (IQR) } \\
\text { Premature infants, } n(\%)^{\mathrm{a}, \mathrm{c}}\end{array}$ & $\begin{array}{l}38(4) \\
11(31)\end{array}$ & $\begin{array}{r}40(1) \\
2(9)\end{array}$ & $\begin{array}{r}40(1) \\
1(3)\end{array}$ \\
\hline $\begin{array}{l}\text { Birth weight, g, median (IQR) })^{\mathrm{a}, \mathrm{b}} \\
\quad \text { Low birth weight newborns, } n(\%)^{\mathrm{b}, \mathrm{c}}\end{array}$ & $\begin{aligned} 2,735 & (640) \\
7 & (22)\end{aligned}$ & $\begin{array}{c}3,500(472) \\
\quad 1(5)\end{array}$ & $\begin{array}{l}3,630(450) \\
0\end{array}$ \\
\hline $\begin{array}{l}\text { Age when doubled birth weight, months, median }(\mathrm{IQR})^{\mathrm{a}, \mathrm{b}} \\
\text { Infants with prophylactic iron supplementation, } n(\%)^{\mathrm{c}}\end{array}$ & $\begin{array}{l}3(1) \\
7(21)\end{array}$ & $\begin{array}{l}4(2) \\
1(5)\end{array}$ & $\begin{array}{l}5(1) \\
3(12)\end{array}$ \\
\hline $\begin{array}{l}\text { Parents age, years, median (IQR) } \\
\text { Mother }^{\mathrm{a}} \\
\text { Father }^{\mathrm{a}}\end{array}$ & $\begin{array}{l}31(4) \\
32(4)\end{array}$ & $\begin{array}{l}30(4) \\
33(6)\end{array}$ & $\begin{array}{l}31(3) \\
35(5)\end{array}$ \\
\hline $\begin{array}{l}\text { Parents with high education, } n(\%) \\
\text { Mother } \\
\text { Father }^{\mathrm{c}}\end{array}$ & $\begin{array}{l}28(93) \\
22(85)\end{array}$ & $\begin{array}{l}18(86) \\
13(76)\end{array}$ & $\begin{array}{l}28(97) \\
22(92)\end{array}$ \\
\hline Anemic mothers in pregnancy, $n(\%)^{\mathrm{c}}$ & $13(36)$ & $10(50)$ & $9(31)$ \\
\hline
\end{tabular}

${ }^{a}$ Non-normal distribution, Kruskal-Wallis rank sum test applied.

${ }^{\mathrm{b}}$ Statistically significant with $p<0.05$.

'Pearson's chi-squared test or Fisher's exact test applied, when appropriate.

IDA, iron deficiency anemia; IQR, interquartile range.

breastfed, but there was a tendency with no statistical difference for healthy children to have formula introduced in addition to BM more often at sixth month of age than the IDA infants and IDA children ( $n=7$ [22\%], $n=1$ [3\%] and $n=3$ [13\%], respectively; $p=0.05$ ) (Fig. 2). Some subjects were given water-based liquids from the first month, with rapidly increasing rates from the third month without significant differences between the groups. Exclusive breastfeeding rates in the first 6 months were similar among all groups and sharply declined in the fifth month when complementary foods were introduced (Fig. 1). The median duration of exclusive breastfeeding was 4 (4) months and did not differ

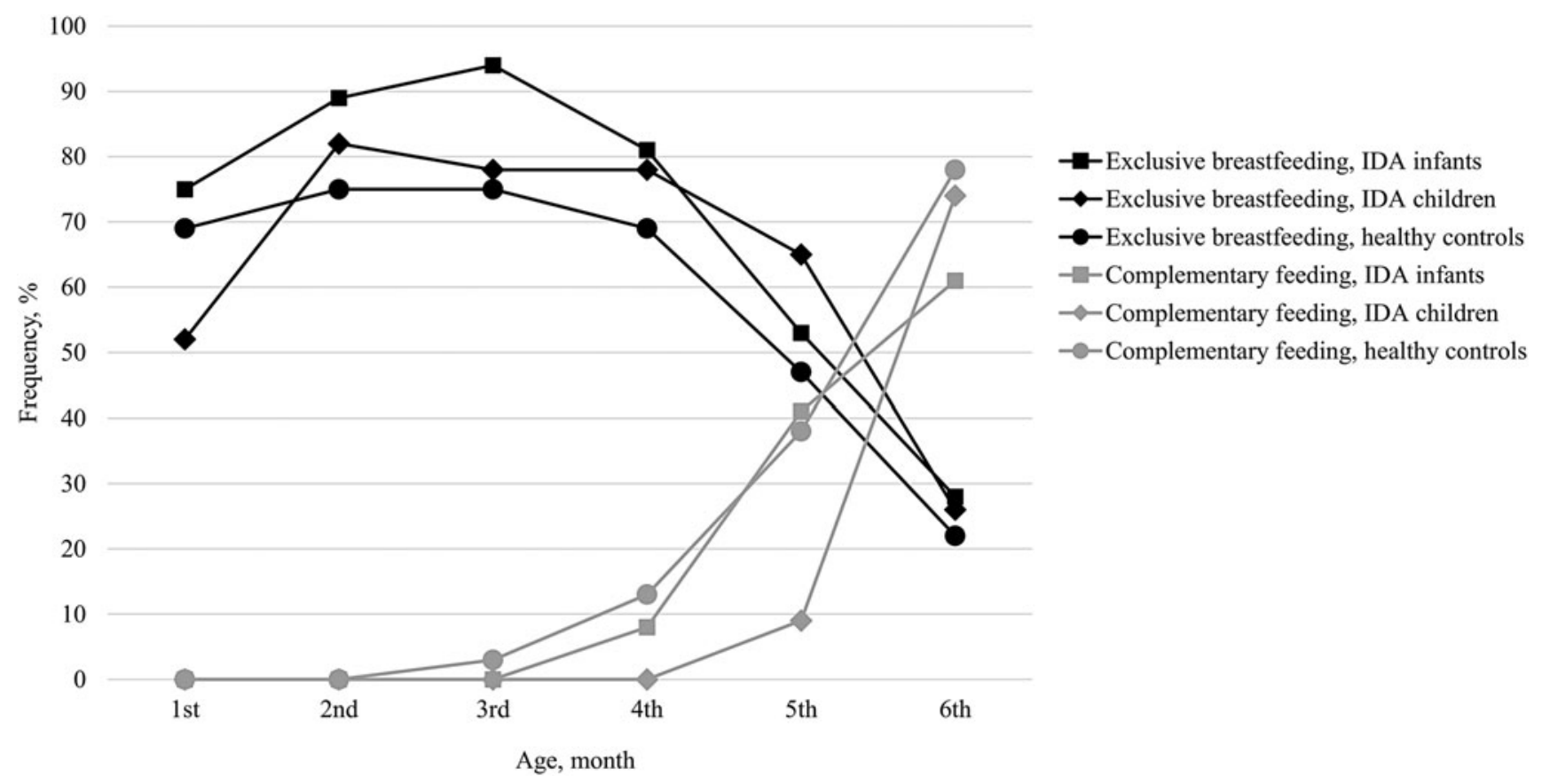

FIG. 1. Frequency of IDA infants and children being exclusively breastfed and introduced complementary feeding during first 6 months of life compared with healthy controls. IDA, iron deficiency anemia. 


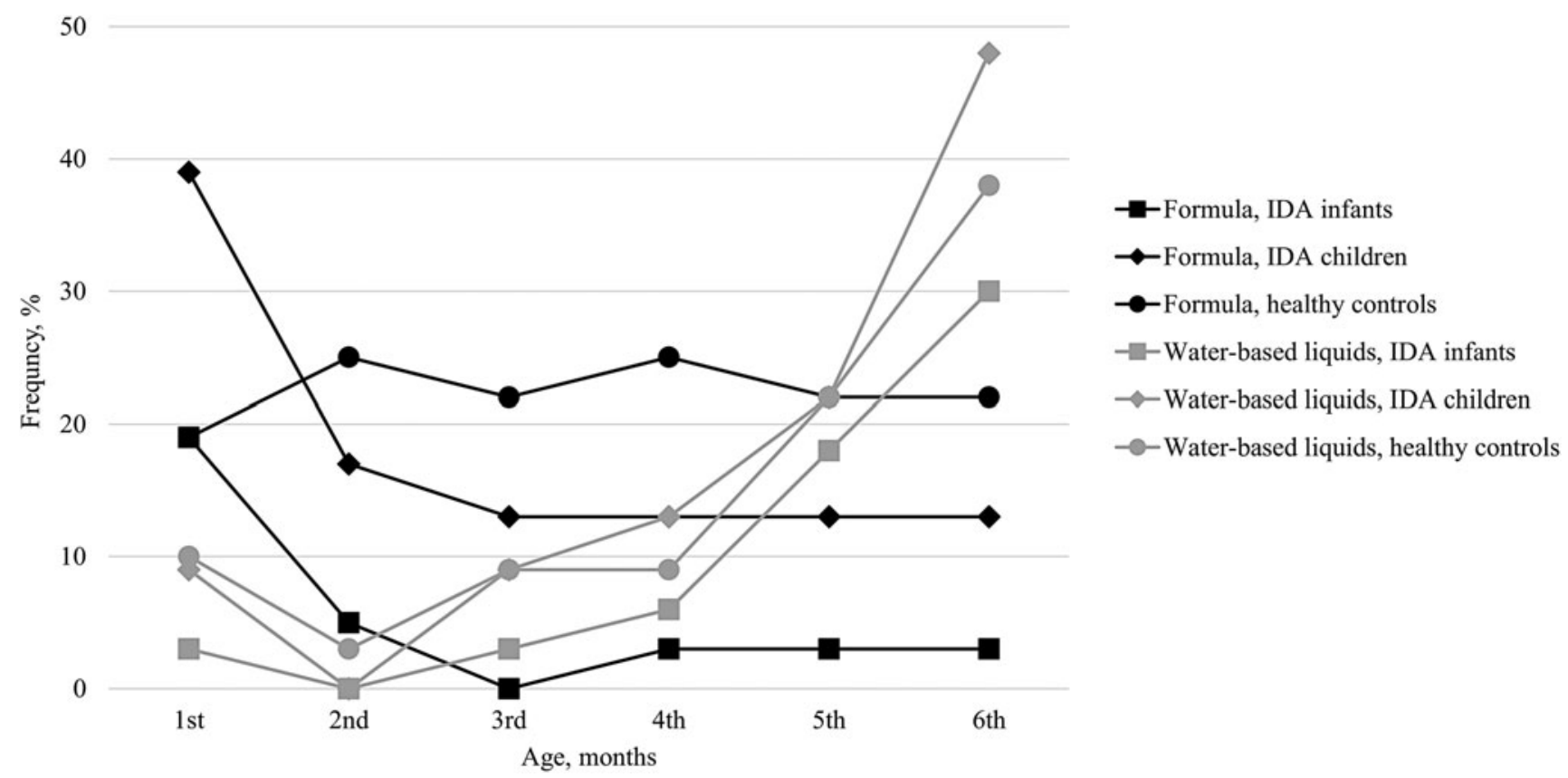

FIG. 2. Frequency of IDA infants and children consuming formula and water-based liquids during first 6 months of life compared with healthy controls.

between the groups. Only a small number of study participants were exclusively breastfed during the entire first 6 months of life (IDA-In: $n=6$ [17\%], IDA-Ch: $n=3$ [13\%], and HC: $n=5[16 \%], p>0.05)$.

The frequency of study participants consuming complementary foods at 6 months of age also did not differ (IDA-In: $n=20$ [61\%], IDA-Ch: $n=17$ [74\%], and HC: $n=25$ [78\%]; $p>0.05$ ) (Fig. 1). Vegetables were introduced first followed by fruits and berries, cereals, meat, fish, eggs, and dairy products. IDA children were given meat later than other study participants (IDA-Ch at 7 [0.5] months, IDA-In at 6 [1.8] months, and $\mathrm{HC}$ at $6[1]$ months, $p<0.05$ ).

Diet diversity increased during the second half-year of life in all groups, but was the lowest in IDA infants, both at 6-8 and 9-11 months $(p<0.05)$ (Fig. 3). A small number of study participants were given cow's milk before the age of 12 months, but a rapid increase in the consumption of sugaradded products (in particular, sweetened dairy products) was observed in the second half of infancy (Fig. 4). At the age of 6-11 months, all IDA infants continued to be breastfed, but three $(13 \%)$ IDA children and four $(13 \%)$ healthy controls were already weaned $(p<0.05)$.

During the second and third year of life, diet diversity and the products consumed by IDA children and healthy controls did not differ significantly. The majority of IDA children and healthy controls consumed cereals (IDA-Ch: $n=19$ [90\%] and HC: $n=17$ [100\%], $p>0.05$ ), vegetables (IDA-Ch: $n=19$ [90\%] and HC: $n=15$ [88\%], $p>0.05)$, and fruits and berries (IDA-Ch: $n=18$ [86\%] and HC: $n=14$ [82\%], $p>0.05$ ) every day. Nevertheless, fewer children consumed meat every day (IDA-Ch: $n=15$ [71\%] and HC: $n=11$ [65\%], $p>0.05$ ). Indeed, there were only six (29\%) IDA children and four (24\%) healthy controls who consumed four food groups every day. Although consumption of cow's milk did not differ between the groups (IDA-Ch: $n=11$ [48\%] and HC: $n=10$ [56\%]), there were two (9\%) IDA children who consumed $>400 \mathrm{~mL}$ cow's milk (aged 13 and 23 months) and one (4\%) IDA child who consumed $\sim 2,000 \mathrm{~mL}$ cow's milk (aged 32 months).

\section{Discussion}

We are the first to focus on breastfeeding practices and early-life dietary habits in relation to IDA in Lithuania based on WHO recommendations. Mild and moderate IDA was the most prevalent among study participants. ${ }^{11,15}$ Although lower socioeconomic status and education are tightly linked to nutritional anemia, ${ }^{2}$ we did not find this association in our study cohort. Nevertheless, this fact only highlights the importance of the problem in Lithuania: even children living in higher socioeconomic (as demonstrated by the educational level of the parents) conditions suffer from IDA.

In accordance with studies conducted in other European countries, ${ }^{16-18}$ premature and LBW newborns developed IDA in their first year of life. They are known to have lower iron stores at birth, higher iron needs for increasing body (i.e., storage iron), red cell (i.e., hemoglobin) mass and thus deplete iron stores earlier, ${ }^{5}$ but only three IDA infants in our group were given prophylactic iron supplements. As observed in other studies, ${ }^{19}$ we also revealed that IDA infants doubled their weight earlier than other participants and were more vulnerable to inappropriate dietary habits. These results suggest that recommendations of enteral iron supplementation for IDA-risk groups (preterm and LBW infants, not forgetting those term infants who double their birth weight before the age of 6 months) should be strictly followed in Lithuania.

Major gaps in breastfeeding practice and the introduction of other foods were observed by analyzing nutritional data. In contrast to the WHO recommendations, ${ }^{3}$ only one-third of 


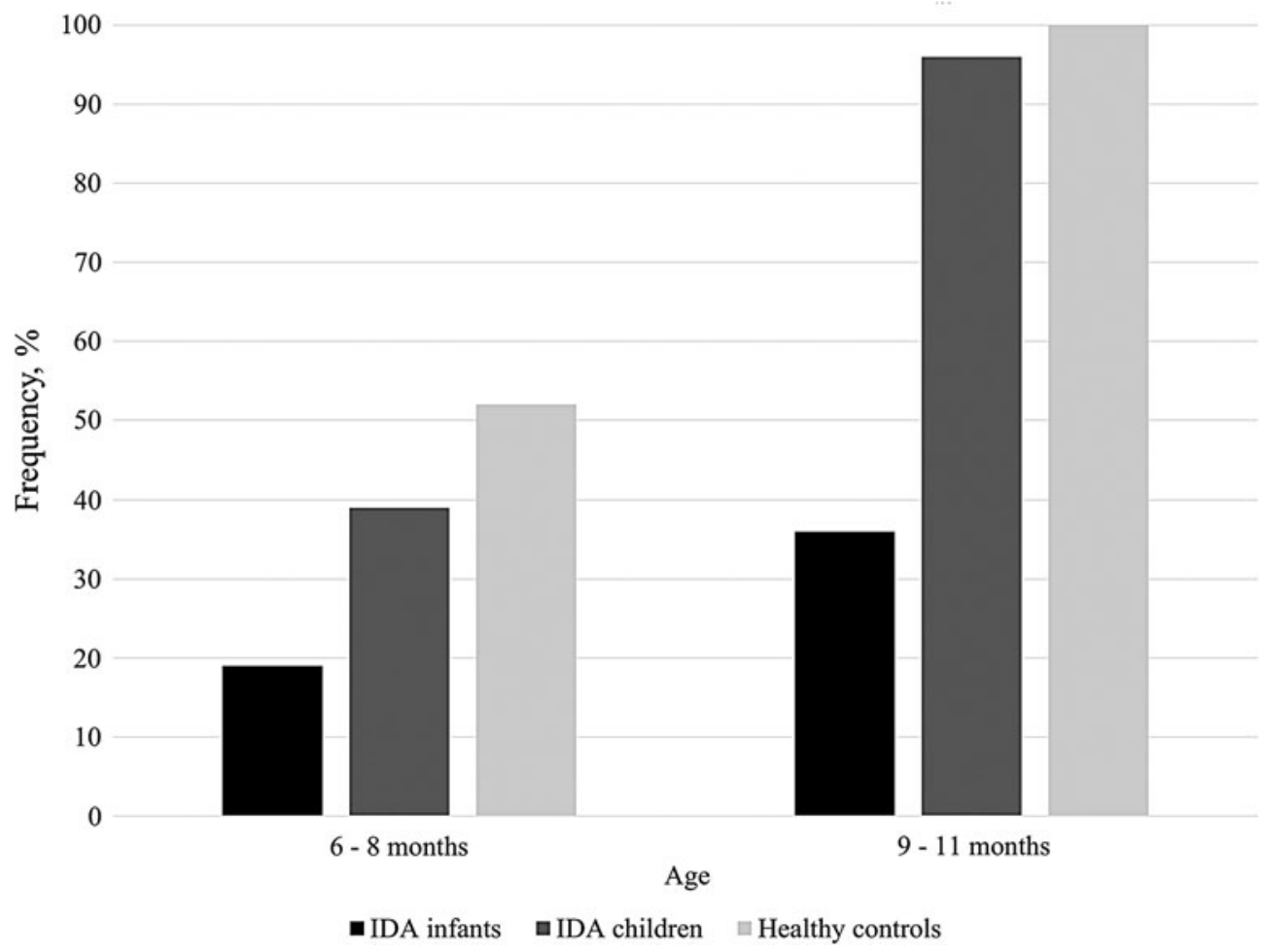

infants were exclusively breastfed at 6 months of age. These observations are consistent with national reports. ${ }^{20}$ Indeed, we expected to find lower rates of exclusive breastfeeding for the full 6-month period. These data were similar to neighboring Latvia $(16.4 \%)^{21}$ and Estonia (26.4\%). ${ }^{22}$ This sub- optimal duration of exclusive breastfeeding increases the risk of infections (especially in infancy), ${ }^{23}$ which may disrupt iron transport to the bone marrow for erythroid cells precursors, and leads to the development of anemia in inflammation. ${ }^{24}$ Furthermore, suboptimal duration of exclusive

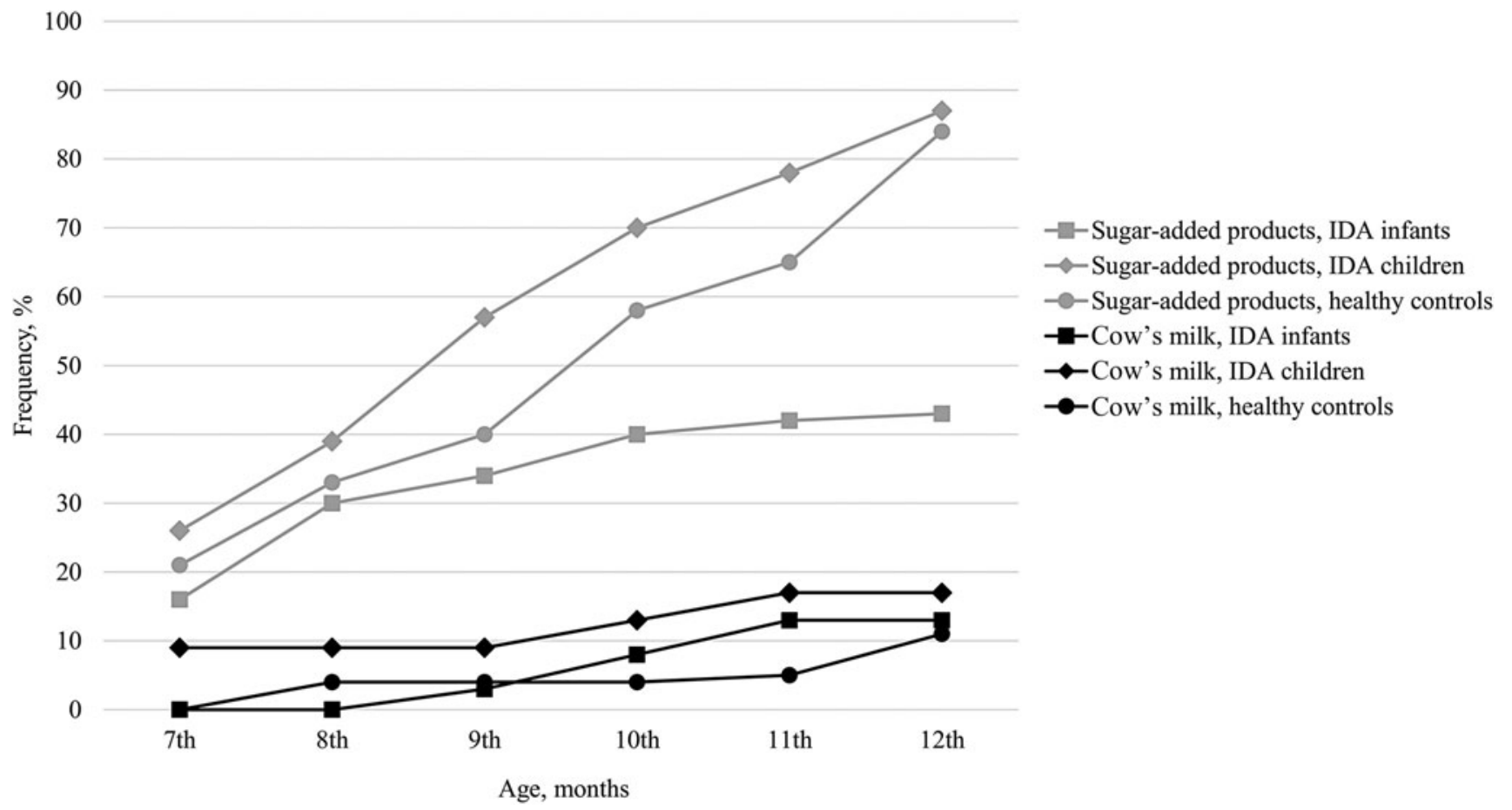

FIG. 4. Frequency of IDA infants and children consuming cow's milk and sugar-added products during the second 6 months of life compared with healthy controls. 
breastfeeding is associated with shorter periods between pregnancies, which may, in turn, compromise maternal iron stores. $^{23,25}$

Those mothers who did not breastfeed exclusively supplemented their children's diet with formula. Cow's milk was introduced only to a small number of children in the second half of infancy. Similar trends were observed in other European countries, ${ }^{26,27}$ with an increasing awareness of higher IDA risks in infants consuming cow's milk. ${ }^{28}$ Cow's milk is not recommended for children $<12$ months of age because of its low iron content, inhibition of iron absorption, and increasing occult blood loss. ${ }^{29}$

Consumption of water-based liquids was common among study participants, increasing after 3 months of age. According to $\mathrm{WHO}$, exclusive breastfeeding on demand provides all necessary liquids for the infant along with highbioavailable microelements and meets the nutrient needs of term infants during the first 6 months of life. ${ }^{30}$ Alarmingly, supplementation with water-based liquids decreases the consumption of nutritious liquids (i.e., human milk) and foods. This, in turn, may alter the nutritional status of the infant. $^{31}$

Thorough analysis of liquids consumed during the first 6 months allowed us to clearly define those participants who were breastfed exclusively; we did not find an association between the consumption of human milk and IDA. Similar results were found in Icelandic infants, when iron status was the most dependent on birth weight (positively) and growth velocity in infancy (negatively) and exclusive breastfeeding did not increase the risk of anemia. ${ }^{26,32}$ Nevertheless, although statistical significance was not achieved, we noticed that IDA children and healthy controls in our study were more likely to receive formula in addition to BM. This could increase their body iron stores as seen in Icelandic children, ${ }^{26,32}$ as formula is fortified with iron due to low iron bioavailability and iron-replete infants are unable to downregulate iron absorption from foods throughout the first half of infancy. ${ }^{33}$ Unfortunately, excess iron intake in iron-replete infants is associated with decreased growth, increased infectious diseases risk, and altered homeostasis of other microelements. $^{34}$ Exclusive breastfeeding for 6 months with introduction of nutritious complementary foods thereafter is seen as the most important measure to reduce the risk of nutritional anemias. ${ }^{2}$

Nevertheless, majority of study participants were introduced to complementary foods earlier than recommended by WHO. The median age and frequency with which complementary foods were introduced did not differ between the groups and we did not observe positive effects of early complementary feeding on reduced risks of ID and IDA. In this study, introduction of complementary foods followed a common pattern when plant-based products were introduced first and followed by animal-based products. ${ }^{27,35}$ Only IDA children were given meat later than IDA infants and healthy controls. In fact, this delay could lead to IDA, as meat is a source of high bioavailable iron, which also increases iron absorption from other foods. ${ }^{36}$ Thus, a diverse diet high in energy and micronutrients is essential for a fast-growing body.

Diet diversity at 6-8 months was significantly lower in IDA infants and did not increase in the 9- to 11-month period. We may speculate that IDA infants were already iron defi- cient at the introduction of complementary foods and this negatively affected mother-infant interaction and led to poorer feeding practices. ${ }^{37}$

Although the consumption of cow's milk was rather low among study participants and played a significant role only in a small number of IDA cases, we observed a sharp increase in the consumption of sugar-added products in the second half of infancy (especially in IDA children). Although no significant differences have been identified between groups, this paves the way for further research. According to the study representing dietary habits of Lithuanian preschool children, almost 70\% children aged 12-36 months consume sugar-added products. ${ }^{38}$ Usually these products are high in energy, resulting in higher weight gain and, in turn, higher micronutrient needs, but children receive less iron, as well as vitamin $\mathrm{E}$, niacin, calcium, and zinc. $^{39}$ The latter finding deserves a particular concern, as majority of IDA children and even healthy controls had inadequate daily diet diversity during the period of 12-36 months of age.

In accordance with previous studies, ${ }^{15,19}$ there were more boys in the IDA infants group. Other research groups also showed that iron status in boys was more affected by growth velocity and nutritional habits, and this may be partially explained by hormonal differences between the genders. ${ }^{26}$

\section{Conclusions}

Low compliance with the WHO recommendations on breastfeeding and complementary feeding shows an urgent need for nutritional counseling in early childhood. Actions for supporting exclusive breastfeeding for the first 6 months of life, increasing diet diversity, and reducing the use of nonnutritious drinks and sugar-added foods are needed. In addition, prophylactic iron supplementation for premature, LBW, and fast weight gaining infants should be implemented in clinical practice more efficiently.

\section{Disclosure Statement}

No competing financial interests exist.

\section{References}

1. Kassebaum NJ, Jasrasaria R, Naghavi M, et al. A systematic analysis of global anemia burden from 1990 to 2010. Blood 2014;123:615-624.

2. World Health Organization. Nutritional Anaemias: Tools for Effective Prevention and Control. Geneva: World Health Organization, 2017.

3. Pan American Health Organization. Guiding Principles for Complementary Feeding of the Breastfed Child. Washington, DC: Pan American Health Organization, 2003.

4. Victora CG, Bahl R, Barros AJ, et al. Breastfeeding in the 21st century: Epidemiology, mechanisms, and lifelong effect. Lancet 2016;387:475-490.

5. Domellof M. Meeting the iron needs of low and very low birth weight infants. Ann Nutr Metab 2017;71(Suppl 3):1623.

6. World Health Organization. Optimal Feeding for Low Birth Weight Infants. Geneva: World Health Organization, 2011.

7. Mills RJ, Davies MW. Enteral iron supplementation in preterm and low birth weight infants. Cochrane Database Syst Rev 2012;(3):CD005095. 
8. Long H, Yi JM, Hu PL, et al. Benefits of iron supplementation for low birth weight infants: A systematic review. BMC Pediatr 2012;12:99.

9. Sniukaite Adner D, Gudanaviciene I, Jakubauskiene M, et al. The world breastfeeding trends initiative. Lithuania Report, 2017. Available at www.worldbreastfeedingtrends.org/Generate Reports/countrysubmit.php?country=LT (accessed May 21, 2018).

10. Institute of Hygiene. Health Information Centre. Available at www.hi.lt/en (accessed May 21, 2018).

11. Kiudeliene R. Diagnostic peculiarities of iron deficiency in early childhood [Doctoral dissertation]. Kaunas Medicine University, Kaunas, 2009.

12. World Health Organization. Haemoglobin Concentrations for the Diagnosis of Anaemia and Assessment of Severity. Geneva: World Health Organization, 2011.

13. World Health Organization. Serum Ferritin Concentrations for the Assessment of Iron Status and Iron Deficiency in Populations. Geneva: World Health Organization, 2011.

14. World Health Organization. Indicators for Assessing Infant and Young Child Feeding Practices. Part I: Definition. Geneva: World Health Organization, 2008.

15. Kriviene I. The epidemiology and the main diagnostic aspects of paediatric anaemia [Doctoral dissertation]. Vilnius University, Vilnius, 2008.

16. Schiza V, Giapros V, Pantou K, et al. Serum transferrin receptor, ferritin, and reticulocyte maturity indices during the first year of life in "large" preterm infants. Eur $J$ Haematol 2007;79:439-446.

17. Akkermans MD, van der Horst-Graat JM, Eussen SR, et al. Iron and vitamin D deficiency in healthy young children in Western Europe despite current nutritional recommendations. J Pediatr Gastroenterol Nutr 2016;62:635-642.

18. Vendt N, Grunberg H, Leedo S, et al. Prevalence and causes of iron deficiency anemias in infants aged 9 to 12 months in Estonia. Medicina 2007;43:947-952.

19. Gunnarsson BS, Thorsdottir I, Palsson G. Iron status in 2year-old Icelandic children and associations with dietary intake and growth. Eur J Clin Nutr 2004;58:901-906.

20. Institute of Hygiene. Public health status in Lithuanian municipalities. Available at www.hi.lt/uploads/pdf/leidiniai/Statistikos/ VS_bukle_sav/VS\%20bukle\%202016.pdf (accessed May 21, 2018).

21. Bagci Bosi AT, Eriksen KG, Sobko T, et al. Breastfeeding practices and policies in WHO European Region Member States. Public Health Nutr 2016;19:753-764.

22. National Institute for Health Development. Estonian national dietary survey 2013-2014. Available at http://pxweb .tai.ee/PXWeb2015/pxweb/en/05Uuringud/05Uuringud_09 RTU_1_rinnapiim/RTU122.px/?rxid=f1d16637-484a-44dd9b77-88f2b38ea63f (accessed May 21, 2018).

23. Kramer MS, Kakuma R. Optimal duration of exclusive breastfeeding. The Cochrane Database Syst Rev 2012;(8):CD003517.

24. Anderson GJ, Frazer DM. Current understanding of iron homeostasis. Am J Clin Nutr 2017;106(Suppl 6):1559S-1566S.

25. Dewey KG, Cohen RJ. Does birth spacing affect maternal or child nutritional status? A systematic literature review. Matern Child Nutr 2007;3:151-173.

26. Thorisdottir AV, Thorsdottir I, Palsson GI. Nutrition and iron status of 1-year olds following a revision in infant dietary recommendations. Anemia 2011;2011:986303.
27. O'Donovan SM, Murray DM, Hourihane JO, et al. Adherence with early infant feeding and complementary feeding guidelines in the Cork BASELINE Birth Cohort Study. Public Health Nutr 2015;18:2864-2873.

28. Griebler U, Bruckmuller MU, Kien C, et al. Health effects of cow's milk consumption in infants up to 3 years of age: A systematic review and meta-analysis. Public Health Nutr 2016;19:293-307.

29. Ziegler EE. Consumption of cow's milk as a cause of iron deficiency in infants and toddlers. Nutr Rev 2011;69(Suppl 1): S37-S42.

30. World Health Organization. Protecting, Promoting, and Supporting Breastfeeding in Facilities Providing Maternity and Newborn Services: The Revised Baby-Friendly Hospital Initiative 2018. Implementation Guidance. Geneva: World Health Organization, 2018.

31. World Health Organization. Baby-Friendly Hospital Initiative: Revised, Updated and Expanded for Integrated Care Section 2: Strengthening and Sustaining the BabyFriendly Hospital Initiative: A Course for Decision-Makers. Geneva: World Health Organization, 2009.

32. Thorisdottir AV, Ramel A, Palsson GI, et al. Iron status of one-year-olds and association with breast milk, cow's milk or formula in late infancy. Eur J Nutr 2013;52:1661-1668.

33. Lonnerdal B. Development of iron homeostasis in infants and young children. Am J Clin Nutr 2017;106(Suppl 6): $1575 \mathrm{~S}-1580 \mathrm{~S}$.

34. Lonnerdal B. Excess iron intake as a factor in growth, infections, and development of infants and young children. Am J Clin Nutr 2017;106(Suppl 6):1681S-1687S.

35. Carletti C, Pani P, Monasta L, et al. Introduction of complementary foods in a cohort of infants in Northeast Italy: Do parents comply with WHO recommendations? $\mathrm{Nu}$ trients 2017;9:34.

36. Collings R, Harvey LJ, Hooper L, et al. The absorption of iron from whole diets: A systematic review. Am J Clin Nutr 2013;98:65-81.

37. Armony-Sivan R, Kaplan-Estrin M, Jacobson SW, et al. Iron-deficiency anemia in infancy and mother-infant interaction during feeding. J Dev Behav Pediatr 2010;31:326332.

38. Bartkeviciute R, Baltusyte I, Stukas R, et al. Peculiarities of nutrition among preschool children who do not attend preschool institutions. Public Health 2016;1:76-84.

39. Ruottinen $\mathrm{S}$, Niinikoski $\mathrm{H}$, Lagstrom $\mathrm{H}$, et al. High sucrose intake is associated with poor quality of diet and growth between 13 months and 9 years of age: The special Turku Coronary Risk Factor Intervention Project. Pediatrics 2008;121:e1676-e1685.

Address correspondence to: Audrone Muleviciene, MMed Clinic of Children's Diseases Institute of Clinical Medicine

Faculty of Medicine Vilnius University Santariskiu g. 4 Vilnius 08406 Lithuania

E-mail: audrone.muleviciene@santa.lt 